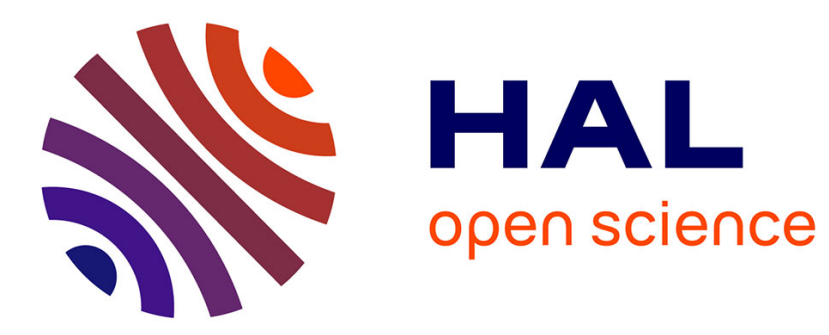

\title{
A method for the determination of the global solar radiation from meteorological satellites data
}

Daniel Cano, Jean-Marie Monget, Michel Albuisson, Hervé Guillard, Nathalie Regas, Lucien Wald

\section{- To cite this version:}

Daniel Cano, Jean-Marie Monget, Michel Albuisson, Hervé Guillard, Nathalie Regas, et al.. A method for the determination of the global solar radiation from meteorological satellites data. Solar Energy, 1986, 37 (1), pp.31-39. hal-00464051

HAL Id: hal-00464051

https://hal-mines-paristech.archives-ouvertes.fr/hal-00464051

Submitted on 16 Mar 2010

HAL is a multi-disciplinary open access archive for the deposit and dissemination of scientific research documents, whether they are published or not. The documents may come from teaching and research institutions in France or abroad, or from public or private research centers.
L'archive ouverte pluridisciplinaire HAL, est destinée au dépôt et à la diffusion de documents scientifiques de niveau recherche, publiés ou non, émanant des établissements d'enseignement et de recherche français ou étrangers, des laboratoires publics ou privés. 


\title{
A METHOD FOR THE DETERMINATION OF THE GLOBAL SOLAR RADIATION FROM METEOROLOGICAL SATELLITE DATA
}

\author{
D. Cano,† J. M. Monget, M. Albuisson, H. Guillard $\ddagger$, N. Regas and L. Wald \\ Centre de Télédétection et d'Analyse des Milieux Naturels, Ecole Nationale Supérieure des Mines \\ de Paris, Sophia-Antipolis, 06560 Valbonne, France
}

(Received 17 April 1985; revision received 1 October 1985; accepted 3 January 1986)

\begin{abstract}
A statistical method is presented for the determination of the global solar radiation at ground level. It makes use of data from the meteorological satellites, which provide extensive coverage as well as adequate ground resolution. In the first step, a reference map of ground albedo is deduced from the time-sequence of satellite images. Then, by comparing the satellite data with the computed albedo map, a cloud coverage index is determined for each ground point of $5 \mathrm{~km} \times 5 \mathrm{~km}$. This index is linearly correlated to the atmospheric transmission factor. The regression parameters are estimated using a training set provided by ground pyranometers. Tests for two different time periods show a good agreement between the actual and model-derived hourly global radiation.
\end{abstract}

\section{INTRODUCTION}

Though the global radiation measurements network in developed countries is still in progress, the average distance between stations in Europe is about $100 \mathrm{~km}$ and is thus too large for the current applications of solar meteorology. In many other parts of the world the networks are even sparser, especially over the oceans.

On the other hand, meteorological satellites provide extensive and frequent observations of the earth-atmosphere system, both in the visible and infrared wavelengths. The ground resolution depends upon the satellite sensor and the latitude of measurements, and varies from 1 to $5 \mathrm{~km}$; the period of observations ranges from 30 minutes to 12 hours.

Adequate processing of these data provides a wealth of information useful in the production of solar energy indices, particularly for those areas where no traditional means of observation are available. Besides their usefulness in solar energy engineering, such global radiation atlases provide new scientific information. For example, they can be used in climatology studies which require accurate data on the ocean heat flux balance, in which the sun radiation plays a major role.

Both the Solar Energy R\&D of the Commission of the European Communities (Project F) and the Agence Française pour la Maîtrise de l'Energie (AFME) are involved in the determination of global radiation using satellite data. This paper presents the work carried out by the authors under these auspices.

Methods for estimating the global radiation at ground level using satellite data can be divided in two categories: a statistical approach based on re-

$\dagger$ Now with Thomson-CSF in Cagnes-sur-Mer.

$\ddagger$ Now with INRIA in Sophia-Antipolis. lations between satellite and ground data and a physical approach using radiative transfer models to formulate a relationship between satellite and ground measurements.

While more likely to be precise when applied to small areas, statistical methods are usually less general and require comparison with ground data. The work of Tarpley[1] is perhaps the best known of these methods. On the other hand, physical methods use simple models, because satellites only measure a few parameters among the many that govern radiative transfer. The best known methods are certainly those of Raschke, Preuss[2] and Gautier et al.[3].

The approach now developed here is of a statistical kind. A training set of ground data is required to determine the parameters of the regression model, which in turn will predict the global radiation. The basic idea of this method is that the amount of the cloud cover over a given area statistically determines the global radiation for that area. Thus, the processing is divided in two steps. A cloud cover index is first derived for each location $(i, j)$, called a pixel, of the original satellite image and subsequently used in a second step for a statistical estimation of the global radiation.

In preparation to the determination of the cloud cover index, a reference map of the planetary albedo for clear sky is constructed and updated daily. The cloud cover index map is then derived from the comparison of the current satellite image and the reference albedo map. Following this determination, the atmospheric transmission factors are computed using pyranometric data and a statistical regression between these factors and the cloud cover index at the same locations is then performed. Finally, the global radiation map is computed on a refined grid using an interpolation technique between ground stations. 


\section{SATELLITE DATA}

The basic remote sensing data are taken from the geostationary satellite Meteosat observations, both in the visible and the thermal infrared spectral ranges. Each satellite image is preprocessed using geometric correction with landmark correlation, noise filtering, and normalization of digital counts by the direct spectral irradiance which would be measured on an horizontal plane located at each pixel under a clear sky.

Because the digital counts can be directly related to the upward radiance, this normalization is equivalent to the computation of a bidirectional reflectance factor. Furthermore, since most continental surfaces may be considered as lambertian for the observation angles under concern (except for water and snow) within a small error, the transformation is equivalent to the computation of an image of the albedo of the system clear sky-ground (planetary albedo for clear sky) with variable cloudiness. For convenience the planetary albedo for clear sky will be called reference albedo in the following. In fact, the exact relationship between the upward radiance and digital count is unknown, because the satellite Meteosat has no calibration. However, the term albedo will be used for convenience.

\section{CONSTRUCTION OF THE REFERENCE ALBEDO MAP}

Generally, the cloud albedo is greater than the ground albedo, except over snow and some desert soils. Usually, one makes use of this fact in the construction of the reference albedo map by assuming that, given a satellite image time-series, the clouds are nonstationary and that the minimum value observed at each pixel will provide a reference albedo map.

In this method, the construction of the albedo map is based on the fact that, if the cloud albedo is greater than the reference albedo, then in a time series of satellite images, the appearance of a cloud in the field of view of the sensor will result in increased measured radiance. Cloud detection can thus be performed by the difference between the cloud induced response and the corresponding signature of the ground under a clear sky.

After the clear sky model of Bourges[4], the global radiation at ground $G_{c}$ at instant $t$ is:

$$
G_{c}(t)=I_{0 j}(\sin v)^{(1+a)},
$$

where $I_{0 j}$ is the extraterrestrial solar irradiance for the day under concern, normal to beam multiplied by 0.7 ; and $v$ is the elevation of the sun.

The parameter $a$ characterizes the total atmospheric transmittance and ranges between 0.14-0.17 depending upon the geographical location[4].

In this work, a value of 0.15 has been chosen and therefore the irradiance measured by the satellite sensor in absence of clouds and coming from the system clear sky-ground of albedo $\rho(t)$ may be expressed by the following:

$$
E(t)=\rho(t) I_{0 j}(\sin \nu)^{1.15} .
$$

The various terms of this formula are considered as random variables, in order to take into account the approximate character of the clear sky model and the instrumental noise. The reference albedo is evaluated at each pixel in a recursive fashion by minimizing the variance of the difference between the measured radiances and the radiances resulting from the clear sky model, the cloudy cases being eliminated at each step.

Under some assumptions, this way of estimating the ground albedo can be justified mathematically[5]. It is assumed that the reference albedo is a stationary random variable $\rho_{g}$ of mean $\bar{\rho}_{g}$ and variance $\sigma_{g}^{2}$, and that the cloud albedo is a stationary random variable $\rho_{c}$ of mean $\bar{\rho}_{c}$ and variance $\sigma_{c}^{2}$. If the apparent albedo is a stationary random variable $X$ equal to $\rho_{g}$ (reference albedo) with a probability $P_{g}$ and equal to $\rho_{c}$ (cloud albedo) with a probability $\boldsymbol{P}_{c}$, it can be shown that the iterative minimization of the variance of the difference between the observed and clear sky model radiances is equivalent to an iterative computation of the mean $\bar{X}$ of the variable $X$, with elimination of the cloudy pixels at each step.

$$
\bar{X}=P_{g} \rho_{g}+P_{c} \rho_{c} .
$$

This convergence property is met if the difference between the means $\bar{\rho}_{g}$ and $\bar{\rho}_{c}$ is much larger than the standard deviation $\sigma_{g}$ and larger than $\sigma_{c}$ :

$$
\begin{aligned}
& \bar{\rho}_{c}-\bar{\rho}_{g} \gg \sigma_{g} \\
& \bar{\rho}_{c}-\bar{\rho}_{g}>\sigma_{c} .
\end{aligned}
$$

In the case of cloud discrimination, those conditions are typically fulfilled, and the iterative average $\bar{X}$ converges to the mean ground albedo value $\bar{\rho}_{g}$. Two important exceptions are snow and some desert surfaces.

The method is illustrated in Fig. 1, which shows the reference albedo map of Europe obtained from ten Meteosat images of May 1979. Of course, if a cloud layer remained stationary in the time-series, the model hypotheses are not fulfilled, and the apparent albedo is the albedo of the cloud, as it is the case over Ireland in Fig. 1. A second example of satellite derived reference albedo map is given in Fig. 2, which relates to the western central part of Africa for the last days of January 1984.

\section{EVALUATION OF THE CLOUD COVER INDEX}

The cloud cover index $n^{t}(i, j)$ at point $(i, j)$ for given time $t$ is defined as a function of the characteristic reference albedo $\rho(i, j)$, the apparent al- 


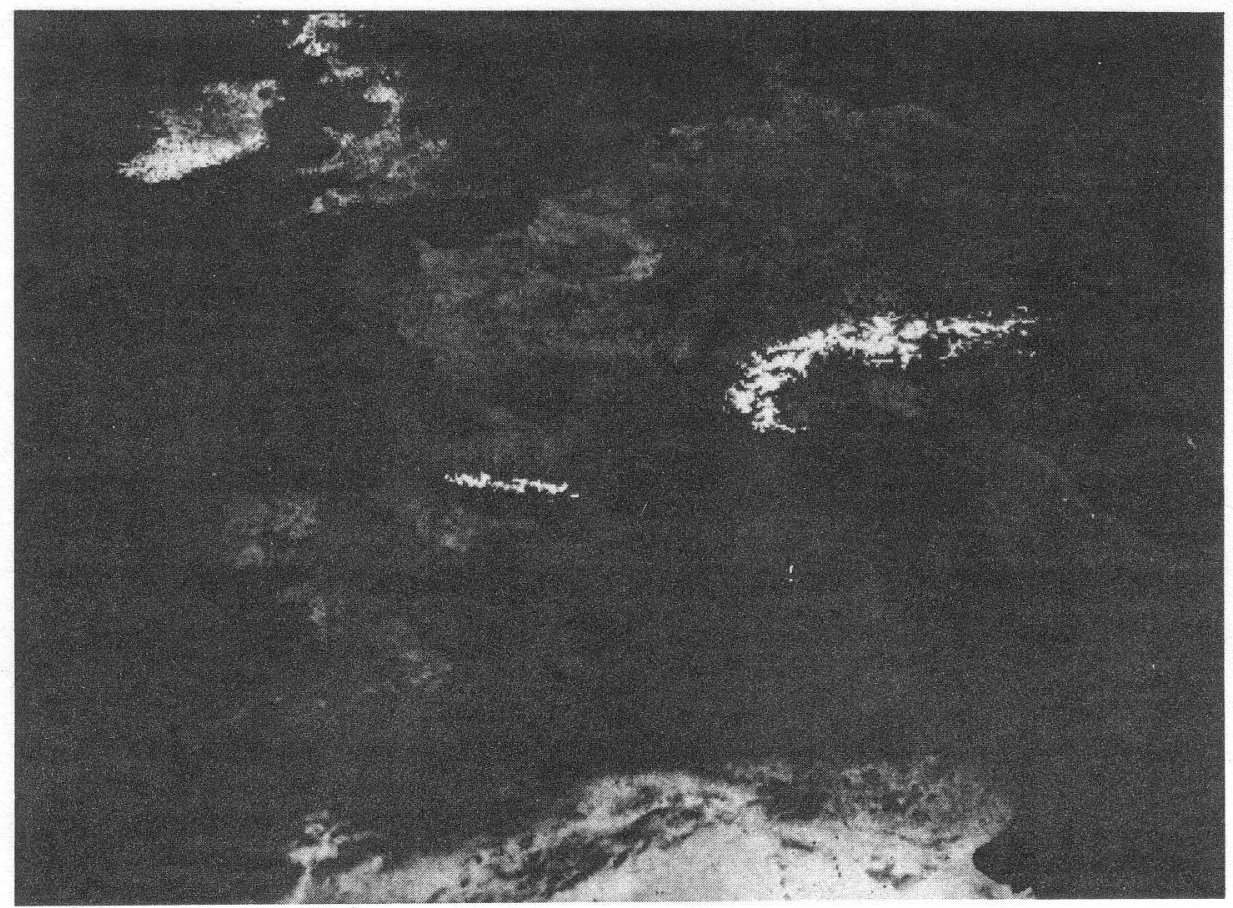

Fig. 1. Map of the reference albedo of Europe obtained from Meteosat data for May 1979. The albedo value increases from black to white. Because the sky was always cloudy over Ireland, the local albedo is very high, and does not represent the ground albedo.

bedo at the same point as measured by the satellite $\rho^{t}(i, j)$, and the average albedo of the cloud tops $\rho_{c}$. It is computed for each pixel using the following formula:

$$
n^{t}(i, j)=\left(\rho^{t}(i, j)-\rho(i, j) /\left(\rho_{c}-\rho(i, j)\right) .\right.
$$

The reference albedo of the Europe area is determined in the previous step for each $5 \times 5 \mathrm{~km}^{2}$ pixel of the Meteosat image by iterative detection and elimination of cloudy areas. The computation of cloud albedo, $\rho_{c}$, is performed using the inverse of the previous algorithm retaining only the cloudy areas. The histogram of this "only cloud" image provides an estimation of $\rho_{c}$ using mode computation.

This cloud cover index ranges from 0 to 1 and can be interpreted as the percentage of the cloud cover per pixel. It also provides an indicator of the transmission of an atmospheric column above the pixel, with low values corresponding to a high transmission factor.

The cloud cover index determination relies on a reliable reference albedo map, which is affected by seasonal variations. In order to take these variations into account, the reference albedo map is updated during the processing by weight averaging a new cloud-free pixel with previously determined cloud-free pixels.

However this method does not perform properly when the reference albedo is of the same order of magnitude as the albedo of the clouds. Over Eu- rope, this is specifically the case over snowy areas. In this case, Cano[5] proposes that an alternate cloud index is defined using the radiance $R^{+}(i, j)$ measured by the satellite in the thermal infrared spectral band:

$$
\left.n^{\prime t}(i, j)=\left(R^{t}(i, j)-R_{s}\right) /\left(R_{c}-R_{s}\right)\right),
$$

where $R_{c}$ is the radiance of the clouds, and $R_{s}$ the radiance of cloud-free snow areas, both determined using image histogram in the thermal infrared. However no further study of this alternate approach was performed. In this case the cloud index may become negative in case of temperature inversion in the lower atmosphere. Also there must be an objective procedure to decide which of the two approaches should be adopted. None of these problems is presently addressed and the method here described does not use this alternative.

\section{STATISTICAL RELATIONSHIP BETWEEN CLOUD COVER INDEX AND GROUND MEASURED TRANSMISSION FACTOR}

The method uses linear regression between the satellite determined cloud cover index and the ground measured transmission coefficient. This simple and efficient approach is based on previous work from Bourges[4], and correlations coefficients determined by Pastre[6] between sunshine duration and cloud cover index.

The total atmospheric transmission factor $K(i, j)$ 


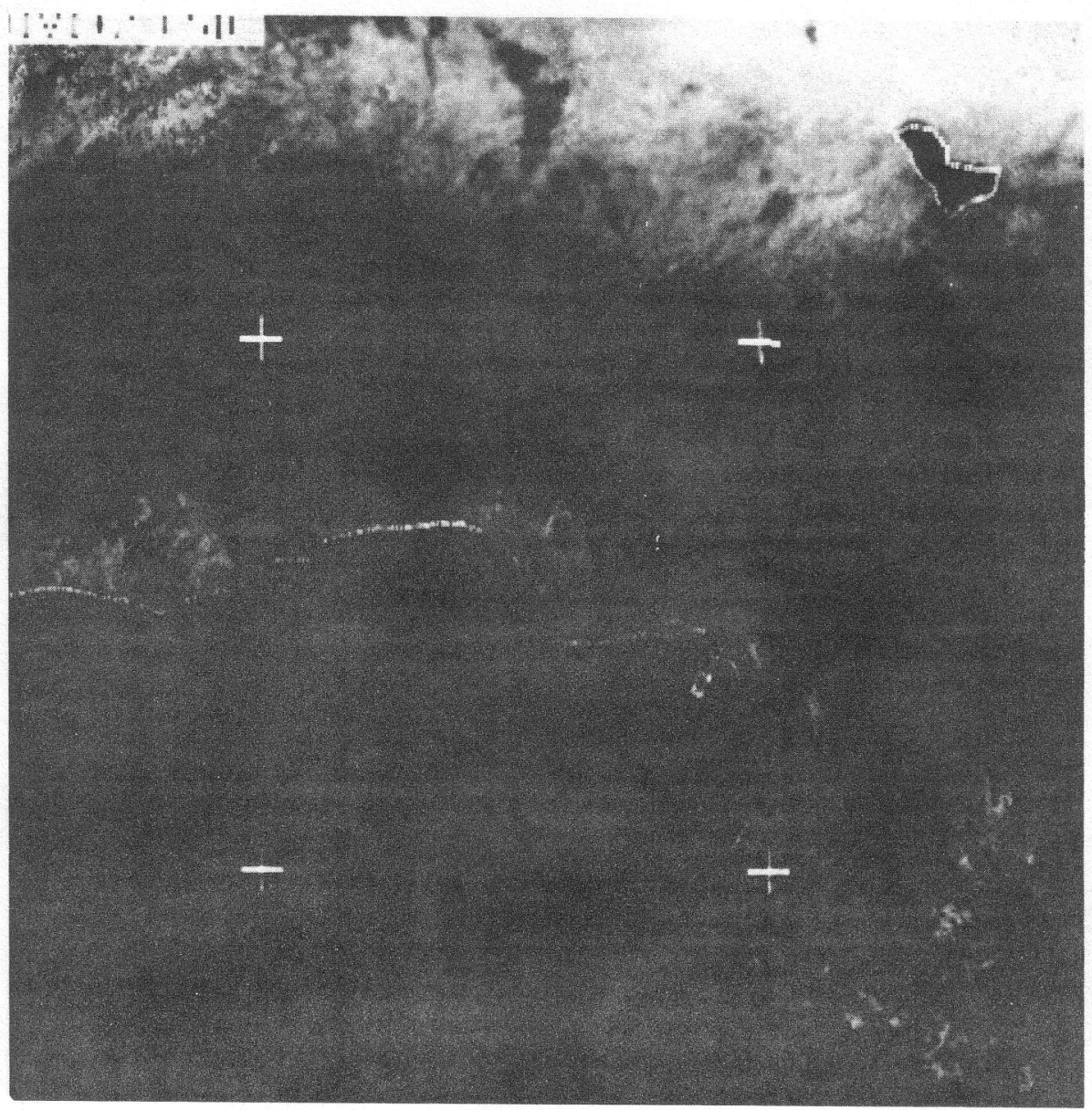

Fig. 2. Map of the reference albedo of western Central Africa, obtained from Meteosat data received in WEFAX format for the last days of January 1984. The albedo increases from black to white.

is defined as the ratio of global radiation at ground on a horizontal surface $G(i, j)$ to the horizontal irradiance outside the atmosphere $G_{0}(i, j)$ :

$$
K(i, j)=G(i, j) / G_{0}(i, j) .
$$

This quantity ranges typically from 0.2 to 0.8 . If one interprets the cloud cover index $n^{t}(i, j)$ as the percentage of pixel covered by clouds, the global ground irradiance at time $t$ is expressed as a linear combination

$G^{t}(i, j)=n^{t}(i, j) G_{b}(i, j)+\left(1-n^{t}(i, j)\right) G_{c}(i, j)$,

where $G_{b}$ and $G_{c}$ are the global ground irradiance for overcast and clear skies, respectively.

For each of these extreme conditions, one can define a transmission factor, respectively $K_{b}$ and $K_{c}$, which is supposed to be constant for a given hour. This realistic hypothesis leads to the following linear relation:

$$
\begin{aligned}
K^{t}(i, j) & =n^{t}(i, j) K_{b}(i, j)+\left(1-n^{t}(i, j)\right) K_{c}(i, j) \\
& =n^{t}(i, j)\left(K_{b}(i, j)-K_{c}(i, j)\right)+K_{c}(i, j) \\
& =a(i, j) n^{t}(i, j)+b(i, j) .
\end{aligned}
$$

In order to test the linear relationship between the cloud cover index and the total transmission factor, measurements of hourly global irradiation during May 1979, provided for 27 French stations by the French Meteorological Office, were reduced to transmission factors and compared to the closest $5 \times 5 \mathrm{~km}^{2}$ pixel in the image with a location root mean square (r.m.s.) error less than half a pixel. The correlation coefficient is almost everywhere greater than 0.80 , thus indicating that the hypothesis of a linear relationship can be relied upon (Fig. 3).

\section{DETERMINATION OF HOURLY GLOBAL RADIATION AT} GROUND

The previous step provides for each pixel and hour time interval $t$, the coefficients $a(i, j)$ and $b(i$, $j$ ), defining a linear regression between the transmission factor $K^{t}(i, j)$ and the cloud cover index $n^{t}(i$, $j$ ) determined from satellite. Once these coefficients are known at the ground stations, a method of interpolation (krigeage) between the stations is applied in order to define the complete field of coefficients $a$ and $b$ for the studied area and for each hour interval. 


\section{ACCURACY OF THE METHOD IN PREDICTING THE GLOBAL RADIATION}

If it is assumed that the field of coefficients $a$ and $b$ for each pixel is stable in time or slowly varying on a seasonal basis, it is thus possible to estimate the transmission factor for each new image as follows:

$$
\hat{K}^{t}(i, j)=a(i, j) n^{t}(i, j)+b(i, j) .
$$

The estimation of the hourly global radiation is then deduced as follows:

$$
\hat{G}_{h}(i, j)=\hat{K}^{t}(i, j) G_{0}(i, j) .
$$

In order to test this model and to estimate its accuracy in predicting hourly global radiation, validations were performed using data from France and Europe. The data sets were split into a training period and an estimation period covering the next 7 days. During the training period, ground measurements of hourly global radiation were used to determine the coefficients $a$ and $b$ for the 27 stations over France in May 1979, and for 89 stations over Europe (April 1982). These coefficients were then used to predict the hourly global radiation during the estimation period for a pixel size $5 \mathrm{~km} \times 5 \mathrm{~km}$. Finally, estimated and measured values were compared and the errors computed.

In the first test, the training period lasted 7 days (5-12 May), and the estimation period ran from 13 to 21 May. The hourly periods were: $8-9 \mathrm{~h}, 10-11 \mathrm{~h}$,
$12-13 \mathrm{~h}$. The correlation coefficient between measured and estimated values is in most cases better than 0.8 (Table 1 and Fig. 4). The r.m.s. ranges from 14 to $72 \mathrm{~J} / \mathrm{cm}^{2}$ ( 39 to $200 \mathrm{Wh} / \mathrm{m}^{2}$ ) with an average value of $42 \mathrm{~J} / \mathrm{cm}^{2}\left(117 \mathrm{Wh} / \mathrm{m}^{2}\right)$.

In the second test, prediction was performed on 24-30 April, using the 1-23 April 1982 for training. The hourly periods were $8-9 \mathrm{~h}, 11-12 \mathrm{~h}$ and $14-15 \mathrm{~h}$. The estimation errors are presented in the form of an histogram for each hourly period and for the whole set of stations (Fig. 5). The r.m.s were respectively 18,24 and $23 \mathrm{~J} / \mathrm{cm}^{2}\left(50,67,64 \mathrm{Wh} / \mathrm{m}^{2}\right)$. The bias (systematic error) is null like for the first test.

The results of the second test are much better, likely due to the greater similarity in conditions during the training and estimations periods.

\section{CONCLUDING REMARKS}

A simple method for estimating the global radiation has been developed and tested. The method, which relies on the prior determination of a reference albedo map, is statistical in nature and avoids the difficult problem of satellite data calibration. In addition to the albedo determination, the foundation of the scheme is the linear relationship between the hourly transmission factor measured at the ground and the cloud cover index computed from the Meteosat data. The root mean square error of reconstruction of radiation at ground stations scattered over France and Europe has been dem-

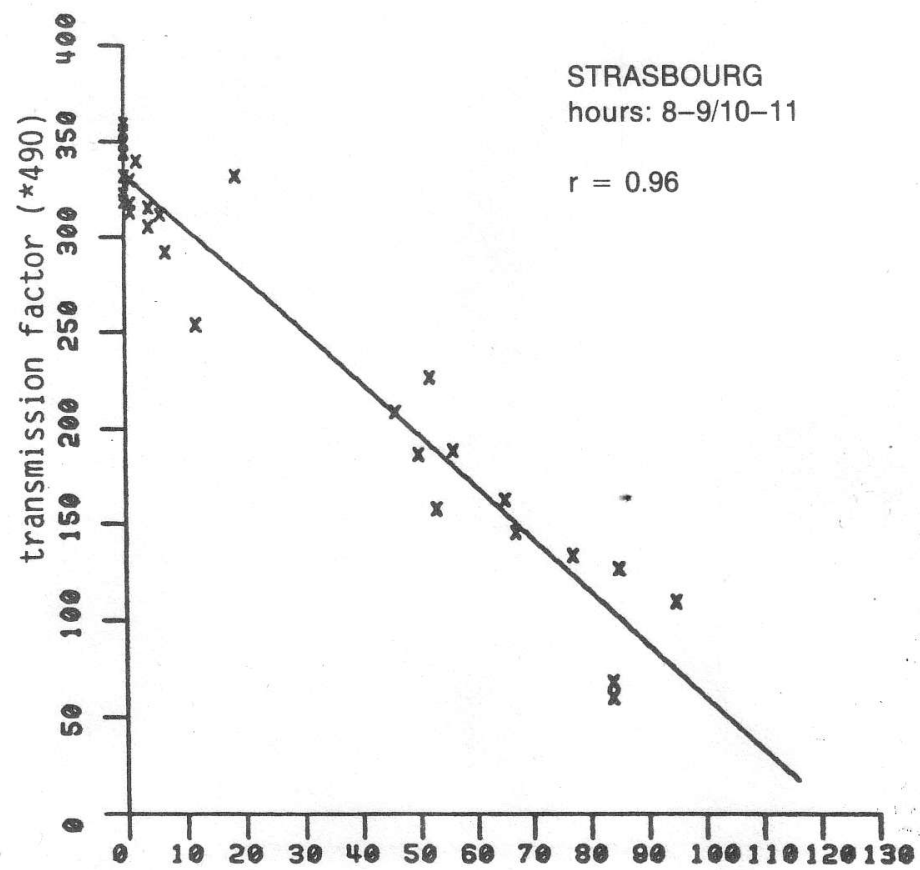

cloud cover index (\%)

Fig. 3. Example of linear regression between satellite cloud index and pyranometer measured transmission factor. 


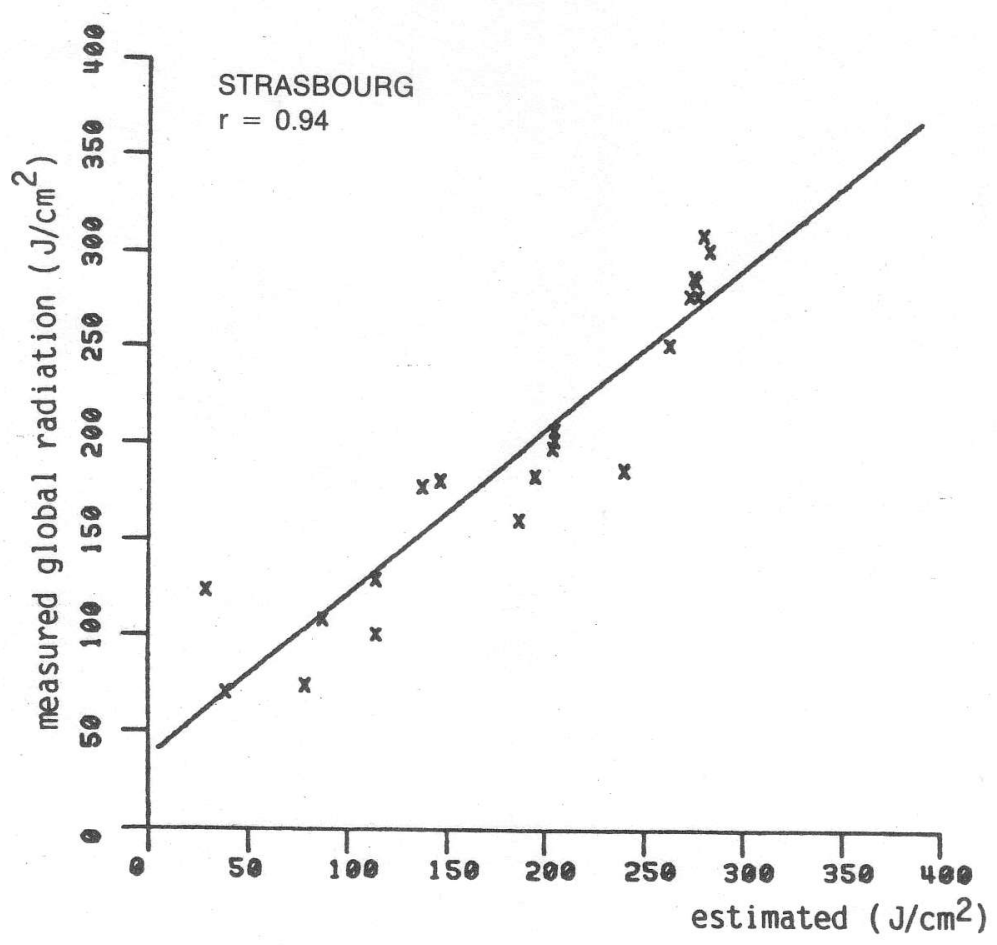

(a)

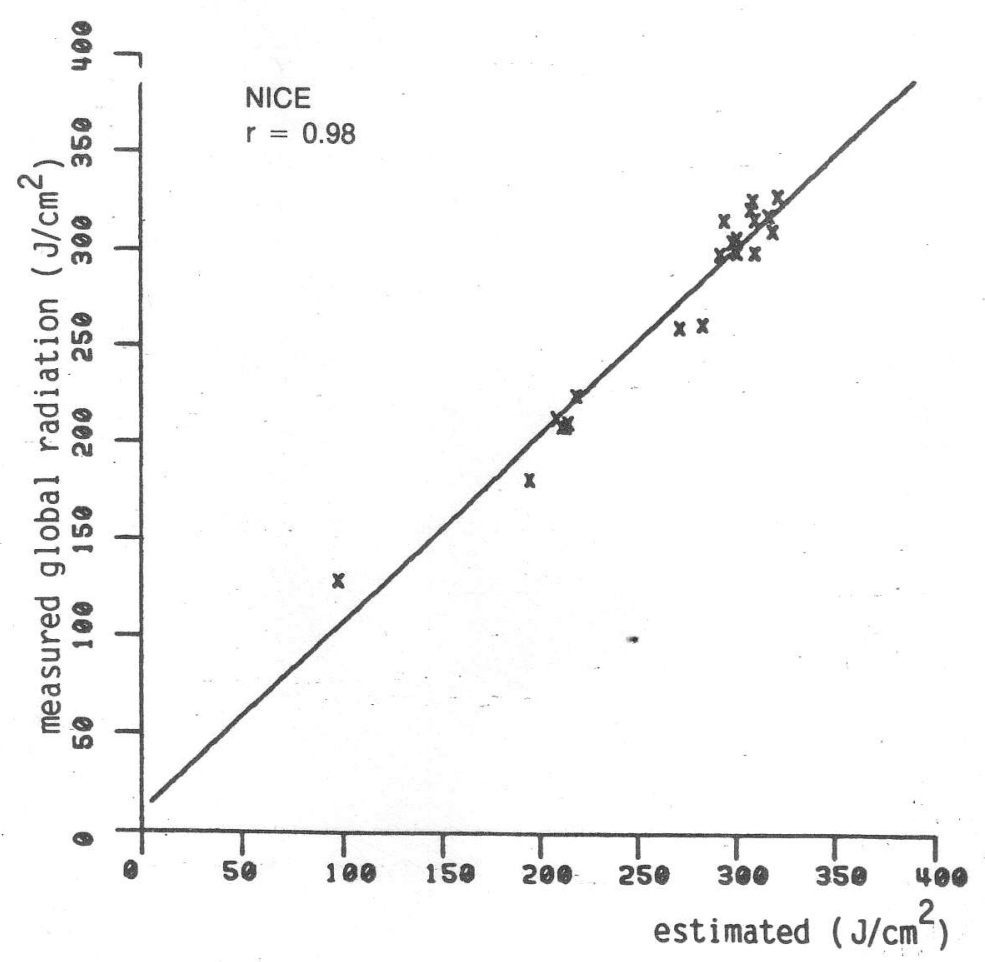

(b)

Fig. 4. Examples of relation between satellite derived and ground measured hourly global irradiation. 


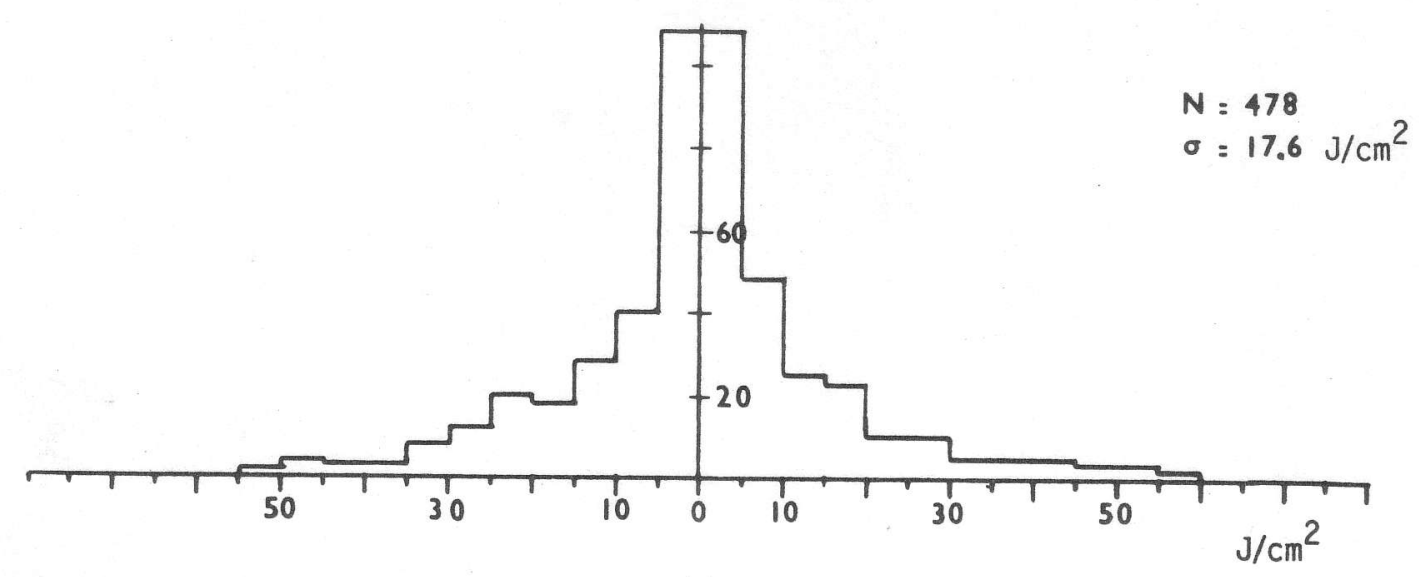

(a)

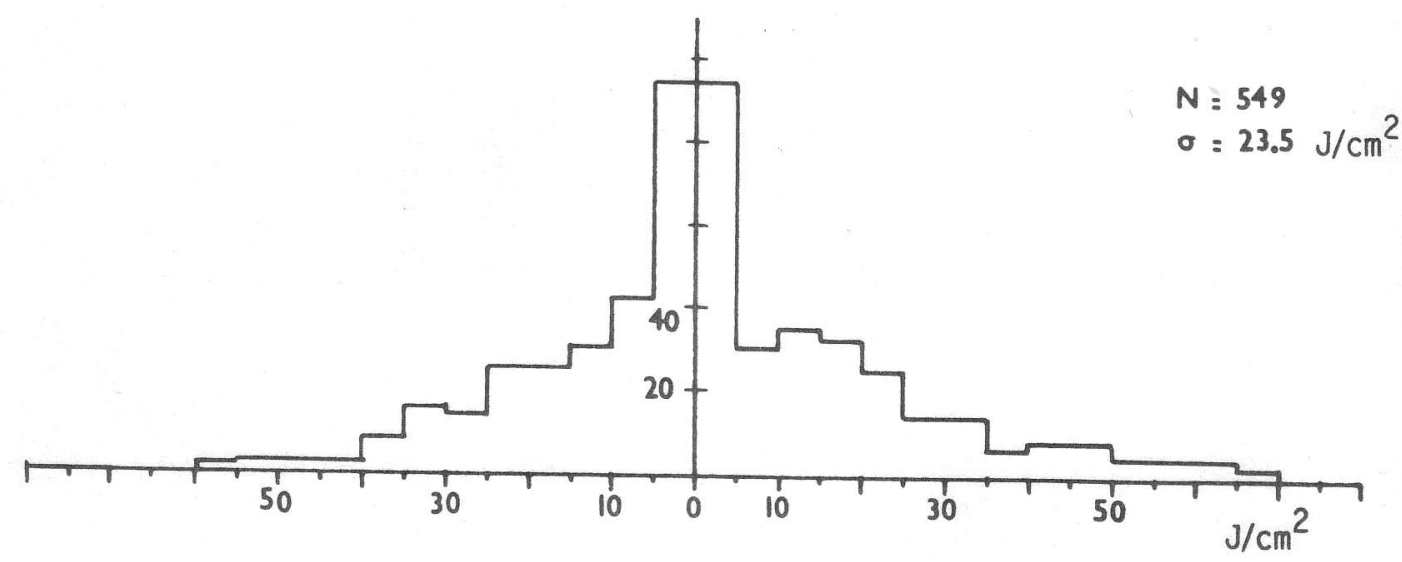

(b)

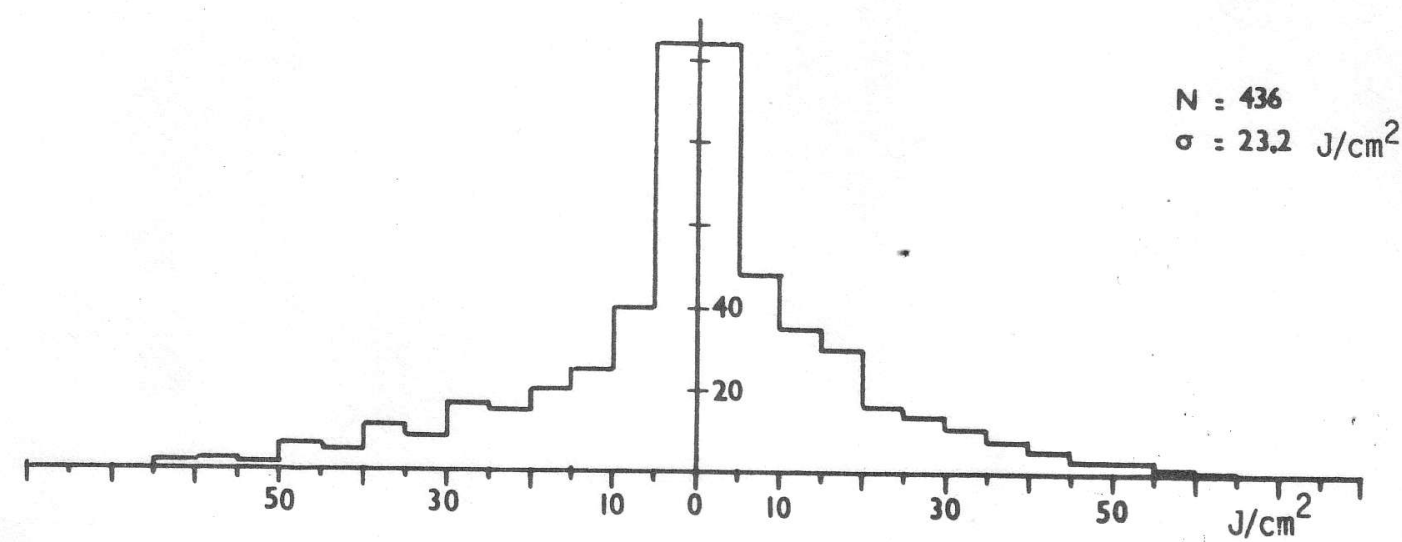

(c)

Fig. 5. Error reconstruction histograms of hourly values of global radiation $(\mathrm{a}: 8-9 \mathrm{~h} ; \mathrm{b}: 11-12 \mathrm{~h} ; \mathrm{c}$ : 14-15h). 
Table 1. Statistical results of comparison between satellite derived and ground measured hourly global radiation using the 27 stations of the French Meteorological Office. Prediction was performed on 13-21 May 1979, period using the previous 7 days for training

\begin{tabular}{|c|c|c|}
\hline STATION & $\begin{array}{l}\text { CORRELATION } \\
\text { COEFFICIENT }\end{array}$ & $\begin{array}{l}\text { R.M.S. } \\
\left(\mathrm{J} / \mathrm{cm}^{2}\right)\end{array}$ \\
\hline 1 & .986 & 14.3 \\
\hline 2 & .968 & 27.1 \\
\hline 3 & .978 & 24.5 \\
\hline 4 & .922 & 34.7 \\
\hline 5 & .938 & 28.1 \\
\hline 6 & .910 & 45.6 \\
\hline 7 & .715 & 55.3 \\
\hline 8 & .956 & 26.4 \\
\hline 9 & .895 & 50.1 \\
\hline 10 & .777 & 69.2 \\
\hline 11 & .914 & 36.8 \\
\hline 12 & .961 & 24.8 \\
\hline 13 & .713 & 72.9 \\
\hline 14 & .964 & 26.3 \\
\hline 15 & .851 & 44.8 \\
\hline 16 & .966 & 22.3 \\
\hline 17 & .943 & 36.3 \\
\hline 18 & .853 & 56.4 \\
\hline 19 & .484 & 72.1 \\
\hline 20 & .863 & 55.1 \\
\hline 21 & .962 & 28.2 \\
\hline 22 & .805 & 60.5 \\
\hline 23 & .919 & 41.4 \\
\hline 24 & .816 & 57.2 \\
\hline 25 & .928 & 36.0 \\
\hline 26 & .806 & 58.5 \\
\hline 27 & .961 & 28.3 \\
\hline AVERAGE & .871 & 42.2 \\
\hline
\end{tabular}

onstrated to be around $30 \mathrm{~J} / \mathrm{cm}^{2}\left(83 \mathrm{Wh} / \mathrm{m}^{2}\right)$ for global hourly values.

These results clearly demonstrate that satellite data can be used successfully for mapping both the global radiation at ground level and the cloud coverage over very large areas, with a ground resolution of $5 \mathrm{~km} \times 5 \mathrm{~km}$. The satellite derived data display details of the mesoclimatic variations of the global radiation over the land. Such information is of particular value in at least five instances. It is a great help in countries where the solar radiation monitoring network is well developed, because it offers an opportunity to interpolate between ground stations and study mesoscale problems. In other parts of the world, such as Africa, satellite data of- fers the only opportunity to map the solar radiation over large areas. They also provide vital new information over the oceans, where, for the moment, only a few measurements are available, and no global radiation map could be produced. Indeed, these satellite derived data should make a substantial contribution to the assessment of the earth radiation budget.

In solar building architecture, $15-50 \%$ of the thermal energy can be derived from solar energy, depending on the seasonal variations. However, this can only be fulfilled after correct dimensioning of storage and regulation devices. These engineering parameters require a precise knowledge of the amount of solar radiation impinging on a wall, a 
glass pane or a roof as an instantaneous value as well as describing its variations over daily and seasonal cycles.

Following this research phase, an operational system should be set up for routine production of global radiation maps or derived data (cloud coverage, albedo). The first effort reported was by Gautier[7] who mapped the hourly global irradiation for the southeastern Canada and northeastern United States of America. She published maps of the daily global irradiation averaged over a month for May and October 1978, and also for thirty days scattered in spring (April-June 1978). In progress is the effort of the Heliosat station team, in Ecole Nationale Supérieure des Mines de Paris in SophiaAntipolis (France). The data from the Meteosat satellite are directly received and processed following a procedure derived from the method hereby presented. The Heliosat station is working since January 1983, and is due to continue in 1985. This scheme produces a map of the hourly global irradiation over Europe three times a day, and, since 1984, over the western central Africa. However, some problems remain and must be solved if the method is to be applied on a worldwide basis. Of particular difficulty are the problems of sand winds and of dry mists in Africa, for which specific studies have just begun.
Acknowledgements-This study was undertaken under funding of the Commission of the European Communities and of the Agence Française pour la Maîtrise de l'Energie. The authors are grateful to the referee who improved the clearness of the present paper.

\section{REFERENCES}

1. J. D. Tarpley, Estimation incident solar radiation at the surface from geostationary satellite data. Journal of Applied Meteorology 18, 1172 (1979).

2. E. Raschke and H. J. Preuss, The determination of the solar radiation budget at the earth surface from satellite measurements. Meteorology Rdsch 32, 18 (1979).

3. C. Gautier, G. Diak and S. Masse, A simple physical model to estimate incident solar radiation at the surface from GOES satellite data. Journal of Applied Meteorology 19, 1005 (1980).

4. G. Bourges, Courbes de fréquence cumulées de l'irradiation solaire globale horaire reçue par une surface plane. Report of Centre d'Energétique de l'Ecole Nationale Supérieure des Mines de Paris, (July 1979).

5. D. Cano, Etude de l'ennuagement par analyse de séquences d'images de satellite. Application à l'évaluation du rayonnement solaire global au sol. Thèse 3ème Cycle. Ecole Nationale Supérieure des Télécommunications (1982).

6. C. Pastre, Développement d'une méthode de détermination du rayonnement solaire à partir des données de Meteosat. La Météorologie, VI, 24, 5 (1981).

7. C. Gautier, Mesoscale insolation variability derived from satellite data. Journal of Applied Meteorology 21, 51 (1982). 